\title{
Study on electro-osmotic consolidation of bentonite reinforced by nano-montmorillonite
}

\author{
Gang $\mathrm{Li}^{1 *}$, Rui Zhang ${ }^{1}$, Jia $\mathrm{Liu}^{2}$, Huanhuan $\mathrm{Li}^{1}$ and Rui $\mathrm{Liu}^{1}$ \\ ${ }^{1}$ Shaanxi Key Laboratory of Safety and Durability of Concrete Structures, Xijing University, Xi' an, Shaanxi 710123, China \\ ${ }^{2}$ School of Geological Engineering and Geomatics, Chang'an University, Xi'an, Shaanxi 710054, China
}

\begin{abstract}
In order to study the effect of nano-montmorillonite on the electro-osmotic consolidation of bentonite, four groups of electro-osmotic consolidation tests were carried out with different content of nano-montmorillonite $(0 \%, 1 \%, 2 \%$ and $3 \%$ ), and the change rules of current, potential, drainage, water content, $\mathrm{pH}$ value and shear strength were analyzed. The results showed that the current, potential and drainage rate decreased with the increase of time. After 48 hours, the current of $\mathrm{T} 2$ decreased by $91.23 \%$, which has the lowest decrease rate. Meanwhile, T2 has the largest total discharge and lowest water content. With the distance increasing from anode, the $\mathrm{pH}$ value increased, while the shear strength decreased. The research results indicated that nano-montmorillonite has a significant effect on the consolidation of bentonite.
\end{abstract}

\section{Introduction}

The soft soils are widely distributed in coastal cities, which have the characteristics of high compressibility, high water content, large void ratio, low shear strength and bearing capacity. For soft soil foundation, traditional ground treatment methods such as surcharge preloading, vacuum preloading and dynamic compaction are far from meeting the demands. Electro-osmotic method is to insert metal electrodes into the foundation and apply direct current, which causes the water in the soil to flow from the anode to the cathode so as to generate electro-osmotic, and to reinforce the foundation with electric energy. Electro-osmotic consolidation method can not only improve the bearing capacity of the foundation in a short time, but also cannot produce the phenomenon of foundation instability. It is an effective treatment method for soft soil foundation at present [1-2].

After the concept of nanotechnology was first proposed in 1959, more and more attention has been paid to nanotechnology in the reinforcement soil. Mohammadi et al[3] concluded that adding nano-soil can improve the liquid limit and plastic limit of soil. Taha et al[4] studied the influence of nano-soil, nano-alumina and nano-copper oxide on the liquid and plastic limit of residual soil, and the results showed that nano-soil can significantly improve the plastic index of residual soil. Luo et al[5] found that adding different amount of nano-alumina can reduce the plasticity index of soil. Pham et al.[6] found that in the presence of electrolyte, PEG coated silica nano-particles had a positive effect on the inhibition of clay swelling. According to the research of Changizi et al[7], adding nano-silica can improve the strength of soil. Correia et al[8] mentioned that the nano-particles can promote the construction of soil matrix together with cementitious materials, and improve the mechanical properties of soil. Niroumand et al[9] pointed out that nano-kaolin instead of ordinary adobe has better performance and higher compressive strength.

At present, there are few research on the electro-osmotic consolidation of bentonite. In this paper, the electro-osmotic consolidation test of bentonite with different content of nano-montmorillonite is carried out to analyze the changes of current, potential, drainage, water content, $\mathrm{pH}$ value and shear strength during the test. The results can provides a scientific basis for the design and construction of the bentonite foundation reinforced by electro-osmotic, and provides a guidance for the future engineering application.

\section{Materials and methods}

\subsection{Test material}

The bentonite produced by Sichuan Renshou Xingda Industry and Trade Co., Ltd, China with the chemical formula of $\operatorname{Nax}\left(\mathrm{H}_{2} \mathrm{O}\right)_{4}\left(\mathrm{AlxMg}_{0.83}\right) \mathrm{Si}_{4} \mathrm{O}_{10}(\mathrm{OH})_{2}$. The bentonite has large water absorption and expansion times, high ion exchange capacity, good dispersion in water medium, high plasticity and strong cohesiveness. Table 1 list the basic physical parameters of bentonite. Nano-montmorillonite was purchased from Hubei Institute of material protection, China. For montmorillonite has unique structural and morphological characteristics, it can be modified to improve its performance, impact resistance, fatigue resistance and so on. It can be used as a new catalytic material, but also

\footnotetext{
*Corresponding author's e-mail: T_bag945@126.com
} 
can improve the processing performance of the material. The modified montmorillonite has a large layer spacing, and the cations adsorbed between layers (hydrated $\mathrm{Na}^{+}$ and $\mathrm{Ca}^{2+}$ ) are easy to exchange with the cations to keep the montmorillonite electrically neutral, so it is a kind of material suitable for electro-osmotic consolidation.

Table 1. Basic physical properties of bentonite

\begin{tabular}{cccc}
\hline$w / \%$ & $d / \mu \mathrm{m}$ & $w_{\mathrm{P}} / \%$ & $w_{\mathrm{L}} / \%$ \\
\hline 1.22 & 49 & 32.1 & 53.7 \\
\hline
\end{tabular}

\subsection{Test equipment}

The test was carried out using a self-designed electro-osmotic model box. The model box is made of 5 $\mathrm{mm}$ thick plexiglass with the size of $270 \mathrm{~mm} \times 120$ $\mathrm{mm} \times 120 \mathrm{~mm}$. There are two $30 \mathrm{~mm}$ compartments on both sides of the model box, and there are $5 \mathrm{~mm}$ diameter drainage holes in the middle of the compartment bottom. The model box can hold $190 \mathrm{~mm} \times 120 \mathrm{~mm} \times 100 \mathrm{~mm}$ soil samples. Iron electrode is selected as the electrode. The electrode size is $120 \mathrm{~mm} \times 100 \mathrm{~mm} \times 2 \mathrm{~mm}$, and there are $4 \mathrm{~mm}$ diameter drain holes distributed on the electrode. Table 2 listed the main test equipment during the test.

Table 2. Test equipment

\begin{tabular}{|c|c|c|}
\hline Equipment & Type & Company \\
\hline DC power supply & IPD-6006SLU & Chengdu Intero Technology Co., Ltd, China \\
\hline Multimeter & VC890D & Shenzhen Shengli Co., Ltd, China \\
\hline Micro vane shear & WXSZB-2.0 & Suzhou Yinganyang Instrument Co., Ltd, China \\
\hline $\begin{array}{l}\text { Combined liquid and plastic limit } \\
\text { tester }\end{array}$ & GSY-2 & $\begin{array}{l}\text { Hebei Dahong Experimental Instrument Co., } \\
\text { Ltd, China }\end{array}$ \\
\hline Table top high speed centrifuge & H3-18 & $\begin{array}{l}\text { Hunan Kecheng Instrument Equipment Co., } \\
\text { Ltd, China }\end{array}$ \\
\hline $\mathrm{pH}$ meter & PHS-3C & $\begin{array}{l}\text { Shanghai Yidian Scientific Instrument Co., Ltd, } \\
\text { China }\end{array}$ \\
\hline
\end{tabular}

\subsection{Test scheme}

In order to explore the influence of different dosage $(0 \%$, $1 \%$, $2 \%$ and $3 \%$ ) of nano-montmorillonite on electro-osmotic, the electro-osmotic promotion effect of nano-montmorillonite is analyzed by measuring the change of current, potential, drainage, water content, $\mathrm{pH}$ value and shear strength after electrified for $48 \mathrm{~h}$ at $24 \mathrm{~V}$. Table 3 listed the test scheme of electro-osmotic consolidation. During the test, the current and displacement were measured every $1 \mathrm{~h}$, the effective potential was measured every $12 \mathrm{~h}$. After the test, the shear strength and water content of the bentonite were measured according to the distribution of the measuring points. Meanwhile, the dried soil sample is crushed and sieved, mixed according to the ratio of 1:5 of soil and distilled water, put the prepared solution into the centrifuge, and take the supernatant for $\mathrm{pH}$ measurement after centrifugation.

Table 3. Electro-osmotic consolidation test scheme

\begin{tabular}{ccccc}
\hline Test number & $t / \mathrm{h}$ & $U_{0} / \mathrm{V}$ & $w_{0} / \%$ & Content/\%o \\
\hline T1 & 48 & 24 & 78.5 & 0 \\
T2 & 48 & 24 & 78.5 & 1 \\
T3 & 48 & 24 & 78.5 & 2 \\
T4 & 48 & 24 & 78.5 & 3 \\
\hline
\end{tabular}

\section{Results and discussion}

\subsection{Effect of nano-montmorillonite on current and potential}

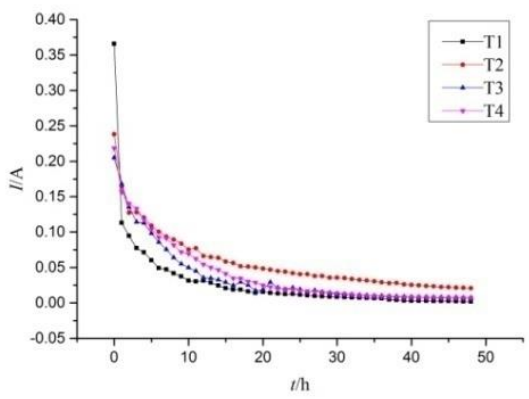

(a) current 


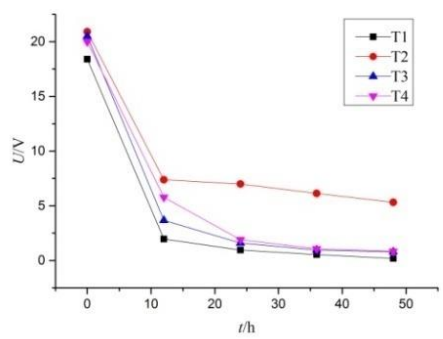

(b) potential

Figure 1. Distribution curves of current and potential in the electro-osmotic test

Figure 1(a) shows the current curves under T1-T4 electro-osmotic test in $48 \mathrm{~h}$. At the beginning of the experiment, the current of T2, T3, T4 with nano-montmorillonite was lower than that of $\mathrm{T} 1$. One hour later, T1 current decreased by $69.22 \%$, T2 by $30.92 \%$, T3 by $18.07 \%$ and T4 by $28.15 \%$. T3 decreased the least in the first $1 \mathrm{~h}$, but the current was lower than $\mathrm{T} 2$ and T4. After 48 hours, the current decrease rate of $\mathrm{T} 2$ was the lowest. It can be seen that T2 current is larger than other groups in the test, indicating that the bentonite with $1 \%$ nano-montmorillonite has small resistance and low current loss rate. Figure 1(b) shows the potential curves under T1-T4 test. It can be seen that the potential of the four tests decreases gradually with the increase of time, and the decreases rapidly at the beginning of the test. The potential of T2 is the largest, which is $74.59 \%$ lower than that of $\mathrm{T} 1$ after 48 hours. It can be concluded that the addition of nano-montmorillonite can reduce the potential and improve the utilization efficiency.

\subsection{Effect of nano-montmorillonite on drainage and water content}

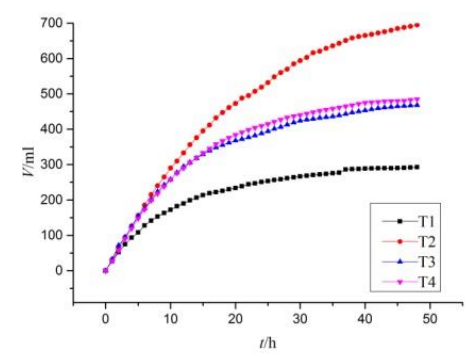

(a) drainage volume

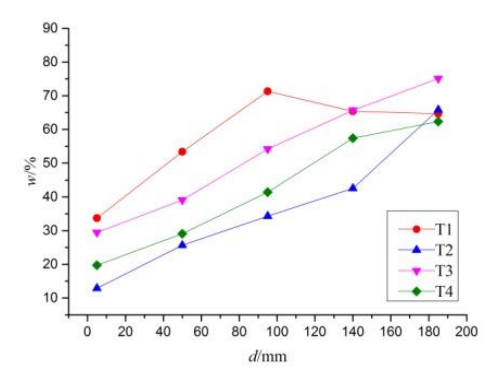

(b) average water content

Figure 2. Distribution curves of drainage and average water content in the electro-osmotic test
Figure 2(a) shows the curves of drainage with time in the electro-osmotic test. It can be seen that the drainage rate with nano-montmorillonite are significantly higher than that without. And the drainage rate of T2 is significantly higher than that of the other three groups, the total drainage volume is $695 \mathrm{ml}$. After 40 hours, the average drainage rate of $\mathrm{T} 2$ reaches $4 \mathrm{ml} / \mathrm{h}$, while that of $\mathrm{T} 1$ is only $0.5 \mathrm{ml} / \mathrm{h}$, which showed that the drainage effect is better when $1 \%$ nano-montmorillonite is added. Figure 2(b) shows the curves of average water content with the increase of distance to anode in the electro-osmotic test. It can be seen that the nano-montmorillonite promotes the drainage process and reduces the water content. The water content of T2 is lower, suggesting that adding $1 \%$ nano-montmorillonite has the best promoting effect on electro-osmotic test.

\subsection{Effect of nano-montmorillonite on $\mathrm{pH}$ value}

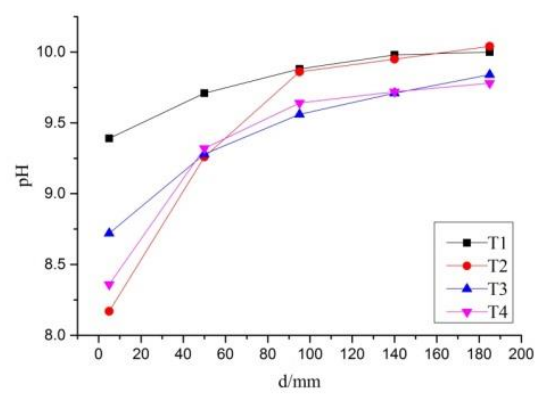

Figure 3. Distribution curves of $\mathrm{pH}$ value in the electro-osmotic test

Figure 3 shows the curves of $\mathrm{pH}$ value with the distance from anode in the electro-osmotic test. It can be seen that the $\mathrm{pH}$ increased with the increasing of the distance from the anode, mainly due to the $\mathrm{H}^{+}$is produced at the anode and the $\mathrm{OH}^{-}$is produced at the cathode. When the $\mathrm{pH}$ value of anode is too low, acidification will reduce the negative charge on the surface of soil particles, which can change into positive charge and affect the electromotive force. Over acidification can even cause reverse electro-osmotic, i.e. from the cathode to the anode. The $\mathrm{pH}$ of T2, T3 and T4 is significantly smaller than that of $\mathrm{T} 1$, which also proves that more $\mathrm{H}^{+}$is generated at the anode and reduces the $\mathrm{pH}$ at the anode. The potential of T2 with 1\%o nano-montmorillonite is the largest, and $\mathrm{H}^{+}$is still generated under high potential, thereby is better than that with other content of nano-montmorillonite. 


\subsection{Effect of nano-montmorillonite on shear strength}

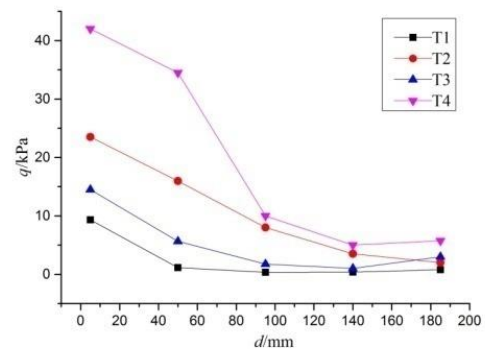

Figure 4. Distribution curves of shear strength in the electro-osmotic test

Figure 4 shows the curves of shear strength in the electro-osmotic test. It can be seen that the water content of the soil with 3\%o nano-montmorillonite is not only the lowest, but also the highest of shear strength. It showed that when the content of nano-materials increases gradually, not only reduced the water content, but also increased the shear strength. Under the action of electric field, water moves from anode to cathode, and the pore water in the soil converges to cathode. After electro-osmotic test, the closer the distance to anode, the higher the shear strength. The shear strength of T3 and T4 increased with the decreasing of the distance from the cathode, which indicated that the higher content of nano-montmorillonite had a better effect on the shear strength.

\section{Conclusions}

(1) The current and potential of the tests decreased gradually with the increase of time. When $1 \%$ nano-montmorillonite was added, the current and the potential was the largest, whereas the decreased rate and potential loss were the lowest.

(2) With the elapse of time, the drainage volume increased and the drainage rate decreased. The addition of nano-montmorillonite has a significant effect on the drainage, and $\mathrm{T} 2$ has the lowest water content and the best consolidation effect.

(3) The $\mathrm{pH}$ value of $\mathrm{T} 2, \mathrm{~T} 3$ and $\mathrm{T} 4$ was significantly lower than that of $\mathrm{T} 1$, and the potential of $\mathrm{T} 2$ at the anode was the largest.

(4) The shear strength decreased with the increasing of the distance from the anode, and the higher content of nano-montmorillonite has a better effect on the shear strength.

(5) The results indicated that the bentonite added nano-montmorillonite could improve the shear strength and the drainage significantly. This provides a guideline for the design and construction of the bentonite foundation reinforced by electro-osmotic consolidation.

\section{Acknowledgements}

This study was supported by the Special Fund for Scientific Research by Xijing University (XJ18T01), and Special Fund for Scientific Research by Shaanxi Provincial Education Department (18JK1199).

\section{References}

1. Zhuang, Y. F. (2016) Theory and design method for electro-osmotic consolidation. Chinese Journal of Geotechnical Engineering, 38(S1): 152-155.

2. Hu, L. M., Wu, W. L., Wu, H. (2010) Theoretical analysis and numerical simulation of electro-osmosis consolidation for soft clay. Rock and Soil Mechanics, 31(12): 3977-3983.

3. Mohammadi, M., Niazian, M. (2013) Investigation of nano-clay effect on geotechnical properties of Rasht clay. Journal of Advanced Science and Technology, 3(3):37-46.

4. Taha, M. R., Taha, O. M. E. (2012) Influence of nano-material on the expansive and shrinkage soil behavior. Journal of Nanoparticle Research, 14(10): 1190.

5. Luo, H. L., Hsiao, D. H., Lin, D. F., Lin, C. K. (2012) Cohesive soil stabilized using sewage sludge ash/cement and nano aluminum oxide. Journal of Transportation Science and Technology, 1(1):83-99.

6. Pham, H., Nguyen, Q. P. (2013) Effect of silica nanoparticles on clay swelling and aqueous stability of nanoparticle dispersions. Journal of Nanoparticle Research, 16(1) :1-11.

7. Changizi, F., Haddad, A. (2015) Strength properties of soft clay treated with mixture of nano- $\mathrm{SiO}_{2}$ and recycled polyester fiber. Journal of Rock Mechanics and Geotechnical Engineering, 29(4): 367-378.

8. Correia, A. A. S., Casaleiro, P. D. F., Rasteiro, M. G. B. V. (2015) Applying multiwall carbon nanotubes for soil stabilization. Procedia Engineering, 102: 1766-1775.

9. Niroumand, H., Zain, M. F. M., Alhosseini, S. N. (2013) The influence of Nano-clays on compressive strength of earth bricks as sustainable materials. Procedia-Social and Behavioral Sciences, 89: 862-865. 